\title{
Reasons to Use and Disclose Use of Complementary Medicine Use - An Insight from Cancer Patients
}

\author{
Kristen Arthur ${ }^{1}$, Juan Carlos Belliard ${ }^{1}$, Steven B. Hardin ${ }^{2}$, Kathryn Knecht ${ }^{3}$, Chien-Shing Chen $^{2} \&$ Susanne \\ Montgomery $^{1}$ \\ ${ }^{1}$ School of Public Health, Loma Linda University, Loma Linda, CA, USA \\ ${ }^{2}$ School of Medicine, Loma Linda University, Loma Linda, CA, USA \\ ${ }^{3}$ School of Pharmacy, Loma Linda University, Loma Linda, CA, USA \\ Correspondence: Kristen Arthur, School of Public Health, Loma Linda University, 24951 North Circle Drive, \\ Nichol Hall Room 1517, Loma Linda, CA, USA. Tel: 1-909-558-1000 ext. 15799. E-mail: karthur@1lu.edu
}

Received: June 19, 2013 Accepted: July 4, 2013 Online Published: October 17, 2013

doi:10.5539/cco.v2n2p81 URL: http://dx.doi.org/10.5539/cco.v2n2p81

Support for this project was provided by the Center for Health Disparities and Molecular Medicine, Loma Linda University, Loma Linda, CA, National Institute of Health, grant \# P20-MD001632, In part supported by: NIH \#1P20MD006988

\begin{abstract}
Studies have shown a high prevalence (40-83\%) of complementary and alternative medicine (CAM) use among cancer patients in the U.S. A cross-sectional, mixed-methods pilot study was completed. This paper focuses on the quantitative analysis conducted on demographic predictors of complementary medicine (CM) use, reasons to use CM, and disclosure to healthcare provider data. Surveys were interview-administered at the Loma Linda University Medical Center Cancer Center. Participants, 18 years or older, were selected from a convenient sample. Eighty-seven percent (87.9\%) of participants reported to have used CM as a cancer treatment and most reported to have used it "to help fight the cancer." Women were eight-times more likely to use prayer. All non-Caucasian and Hispanic participants reported to use CM as a cancer therapy and none reported to use a CM provider. More women (72\%) disclosed their CM use than men $(53.3 \%)$. Different prevalences and predictors exist when differentiating $\mathrm{CM}$ modalities, reasons to use $\mathrm{CM}$ vary by gender, and disclosure proportions vary by gender.
\end{abstract}

Keywords: Complementary and Alternative Medicine (CAM), Complementary Medicine (CM), cancer therapies, disclosure of CAM

\section{Introduction}

Complementary and alternative medicine (CAM) is generally defined as a group of diverse medical and health care systems, practices, and products that are not presently considered to be part of conventional medicine (NCCAM, 2010; Harris \& Rees, 2000). It is estimated that 38\% of all adults in the United States use CAM each year (Barnes, 2008); however, the inclusion of certain CAM items is inconsistent (NCCAM, 2010). Most Americans who use CAM use complementary medicine $(\mathrm{CM})$ as an adjunct to conventional treatments (NCCAM, 2010). Studies have reported that use of CM among patients with a serious illness, such as cancer, is higher than that of the general population and ranges from $40 \%$ to $83 \%$ (Boon et al., 2000; Buettner et al., 2006; Cassileth, Lusk, Strouse, \& Bodenheimer, 1984; DiGianni, Garber, \& Winer, 2002; Ernst \& Cassileth, 1998; Ganz et al., 2002; Greenlee et al., 2009; Habermann et al., 2009; Henderson \& Donatelle, 2004; Lawsin et al., 2007; Lee, Lin, Wrensch, Adler, \& Eisenberg, 2000; Lo, Desmond, \& Meleth, 2009; J. J. Mao, Farrar, Xie, Bowman, \& Armstrong, 2007; J. J. Mao, 2011; Morris, Johnson, Homer, \& Walts, 2000; Richardson, Sanders, Palmer, Greisinger, \& Singletary, 2000; Saxe et al., 2008; Yap, 2004), depending on CM modalities included and the study population (Buettner et al., 2006; J. J. Mao et al., 2007; Saxe et al., 2008). While studies of the use of CM among cancer patients have been increasing, the motivation to use CM, both clinical (Gansler, Kaw, Crammer, \& Smith, 2008; Velicer \& Ulrich, 2008) and psychosocial (Arthur, 2012; Singh, 2005), are not fully 
understood. Better understanding of these reasons can increase provider awareness of CM use in general and may facilitate discussion about CM use between patients and their health care providers (Bell, 2010).

Because certain CM products may interact with conventional cancer treatments and CAM efficacy studies are limited (Hietala et al., 2011; Thomas-Schoemann et al., 2011), it is essential that CM users disclose their use (Pappas \& Perlman, 2002; Richardson, Masse, Nanny, \& Sanders, 2004). Several studies have reported that only $33 \%$ of adult CM users reported CM use to their healthcare provider (Kennedy, 2005; NCCAM, 2010; Robinson \& McGrail, 2004). Among cancer patients, disclosure rates have been reported to be higher than the general population and range from $47 \%$ to $85 \%$, depending on type of CM used (Chao, Wade, \& Kronenberg, 2008; Saxe et al., 2008). One of the main reasons patients did not disclose their CM use or interest in CM was merely because the healthcare provider did not ask (NCCAM, 2010). Similarly, patients are more likely to disclose CM use to their healthcare provider when the provider involved the patient in his/her treatment decisions (Sleath, Callahan, DeVellis, \& Sloane, 2005). Nonetheless, reasons to disclose or not to disclose CM should be further researched, because an environment that promotes two-way communication between patient and healthcare provider is essential (Ben-Arye \& Frenkel, 2008).

Given the frequency of $\mathrm{CM}$ use and yet our limited knowledge as to why cancer patients may seek, use, and disclose CM use, we designed this study to further explore these questions. Specifically, we sought to quantify knowledge, attitudes, perceptions and practices of cancer patients at Loma Linda University Medical Center (LLUMC) towards CM by conducting a mixed-methods pilot study. The study had three phases: (1) to gather and analyze preliminary qualitative data via face-to-face administered interviews (Arthur, 2012), (2) to design an appropriate survey tool, and (3) to gather and analyze quantitative data via face-to-face administered pilot surveys. This paper will report the quantitative analysis conducted on demographic predictors of CM use, reasons to use $\mathrm{CM}$, disclosure to healthcare provider data (including frequencies, reasons for or against disclosure, etc.).

\section{Materials \& Methods}

\subsection{Study Design \& Eligibility}

Surveys were face-to-face interview-administered and conducted by three trained graduate assistants at the Loma Linda University Medical Center (LLUMC) Cancer Center infusion room. LLUMC is a tertiary care, academic medical center that serves a racially and ethnically diverse population from the Inland Empire region of Southern California. Survey administration was triangulated (Denzin, 1970) with respect to day of the week, time of day, patient demographics, and patients' cancer characteristics. For inclusion into the study, participants had to be receiving cancer treatment from LLUMC at the Loma Linda location during the months of June - August, 2010 and be 18 years or older. Participants were selected from a convenience sample. Triangulated data collection (Denzin, 1970) and a heterogeneous group of patients were utilized to reduce selection bias by choosing a sample population that was more representative of the cancer population attending LLUMC (Morgan, 2009; Reeves, 2010).

The study protocol was approved by the Loma Linda University Adventist Health Sciences Center Institutional Review Board. All participants gave informed written consent to participate. Seventy-five percent (75\%) of patients invited to participate agreed to do so and signed written consents to participate in the survey. Medical records for all participants were reviewed.

\subsection{Survey Instrument}

The survey instrument was developed to assess complementary medicine (CM) use, disclosure, beliefs, and perceptions among cancer patients receiving conventional treatment at LLUMC and was developed from qualitative data collected (Arthur, 2012) from the same study population. Participants were asked about past and/or current use of different modalities of CM: dietary change or nutritional status, dietary supplements (including vitamins but non-herbal), green tea, herbal tea, herbs or herbal supplements (not including tea), movement-based relaxation techniques (e.g. yoga or tai chi), other relaxation techniques, meditation, prayer, spirituality (other than prayer), acupuncture/acupressure, use of a complementary and alternative medicine provider (other than an acupuncturist), or other. Examples of relaxation techniques could include guided imagery, deep breathing, music therapy, progressive muscular relaxation, massage, and cognitive-behavioral therapies. If participants expressed uncertainty about the definition or concept of "spirituality," interviewers were prompted to state the National Cancer Institute's definition of spirituality which is: 
Having to do with deep, often religious, feelings and beliefs, including a person's sense of peace, purpose, connection to others, and beliefs about the meaning of life. (NCI) Spirituality has also been more generally defined as the development of inner peace or the foundations of happiness.

\subsection{Assessment of CM Use}

Univariate analysis of different CM modalities was assessed using dichotomous, yes/no outcome variables. The univariate analysis included five different outcome variables: four different modalities of CM (biologically-based therapies, mind-body therapies, prayer, and use of a CAM provider) and use of any CM modality as a cancer therapy. Table 2 illustrates the items that were included in each CM modality. Use of any CM modality as a cancer therapy was a collapsed variable that was "yes" if the participant responded "yes" to using their $\mathrm{CM}$ with the intent to treat physical or emotional side-effects from the cancer and/or cancer treatment, prevent the cancer from recurring, help fight the cancer, or to cure the cancer (Table 2).

Four dichotomous predictor variables were assessed: gender, age (less than 60 years or greater than or equal to 60 years), ethnicity (Hispanic or non-Hispanic), and race (Caucasian or non-Caucasian). All variables were collapsed with the exception of gender. Age was a continuous variable on the survey tool and sixty years was chosen because it was the mean of the study population. Various Hispanic origin ethnicities were collapsed into Hispanic, though the majority of Hispanics were of Mexican-origin. All non-Caucasian races were collapsed since approximately $60 \%$ of the study population was Caucasian and a variety of other minority groups were sampled.

\subsection{Data Analysis}

Data entry was conducted in Microsoft Excel 2007. An alpha-level of 0.05 was used for all analyses. Sample size and power analyses were conducted using SAS Power and Sample Size 3.1. Data analysis was conducted using SAS 9.2. The Proc Freq/all command was used in the univariate analysis to determine odds ratios (OR) and significance.

\section{Findings}

\subsection{Demographic Characteristics}

Thirty-nine females $(67.2 \%)$ and 19 males (32.8\%) were surveyed. Thirteen percent $(13.8 \%)$ of participants were Hispanic and $86.2 \%$ were non-Hispanic. While $60.3 \%$ of participants were Caucasian non-Hispanic, the remaining 39.7\% were racially diverse and included African-Americans, Asians, bi-racial, and (native) American-Indian participants. Female participants' age ranged from 34 to 88 years with a mean of 58.8 years (standard deviation, 13.2). Male participants' age ranged from 41 to 78 with a mean of 62.2 years (standard deviation, 10.9). Overall, the study population was a mid-socioeconomic status group of participants. Seventy-seven percent (77.6\%) of participants reported achieving an educational level of some college or greater and $65.5 \%$ of participants reported a household income of $\$ 50,000$ or greater. Although a higher percentage of women compared to men $(81.6 \%$ versus $73.7 \%)$ reported achieving some college or greater, less women reported having a household income of $\$ 50,000$ or greater $(46.2 \%$ versus $73.7 \%)$. Characteristics are stratified by gender in Table 1.

\subsection{Health Factors}

Of all participants, $27.5 \%$ were diagnosed with breast cancer, $15.5 \%$ were diagnosed with colon/rectal cancer, $10.3 \%$ with lung cancer, $10.3 \%$ with Non-Hodgkin Lymphoma, and $8.6 \%$ with prostate cancer. Twenty-seven percent $(27.6 \%)$ of participants had experienced recurrence and the mean time since diagnosis was 3.26 years. Most participants (84.5\%) had or were receiving combination therapy (two or more conventional therapies, such as chemotherapy, radiation, surgery), whereas $15.5 \%$ of participants were receiving chemotherapy exclusively. Characteristics are stratified by gender in Table 1 . 
Table 1. Characteristics of Study Population

\begin{tabular}{ccc}
\hline Characteristic & $\begin{array}{c}\text { Females } \\
\mathbf{n = 3 9}\end{array}$ & $\begin{array}{c}\text { Males } \\
\mathbf{n = 1 9}\end{array}$ \\
\hline Age (years) & $(\%)$ & $(\%)$ \\
$18-34$ & 5.1 & 0.0 \\
$35-49$ & 20.5 & 15.8 \\
$50-59$ & 28.2 & 5.3 \\
$60-69$ & 25.6 & 47.4 \\
$\geq 70$ & 20.5 & 31.6
\end{tabular}

Ethnicity

$\begin{array}{lll}\text { Hispanic } & 15.8 & 11.1 \\ \text { non-Hispanic } & 84.2 & 88.9\end{array}$

Race

Caucasian, non-Hispanic

$61.5 \quad 57.9$

African-American, non-Hispanic

$\begin{array}{ll}7.7 & 5.3\end{array}$

Chinese, non-Hispanic

$0.0 \quad 5.3$

Filipino, non-Hispanic

$5.1 \quad 0.0$

Other Asian, non-Hispanic

$0.0 \quad 5.3$

Bi-racial, non-Hispanic

$5.1 \quad 0.0$

American-Indian, non-Hispanic

$2.6 \quad 10.5$

Other

$17.9 \quad 13.3$

Education

High school or less

$18.4 \quad 26.3$

Some college or greater

$81.6 \quad 73.7$

Household income

$\begin{array}{lll}\$ 50,000 \text { or less } & 53.9 & 26.3 \\ \geq \$ 50,000 & 46.2 & 73.7\end{array}$

Cancer Diagnosis

Breast

$41.0 \quad 0.0$

Colon/rectal

$15.4 \quad 15.8$

Leukemia

$0.0 \quad 5.3$

Lung

$10.3 \quad 10.5$

Melanoma

$5.1 \quad 5.3$

Non-Hodgkin Lymphoma

$10.3 \quad 10.5$

Ovarian

$10.3 \quad 0.0$

Prostate

$0.0 \quad 26.3$

Other

$\begin{array}{ll}7.7 & 26.3\end{array}$

Experienced recurrence

Yes

$34.2 \quad 15.8$

No

$65.8 \quad 84.2$

Conventional Treatment

$\begin{array}{lll}\text { Chemotherapy, exclusively } & 15.4 & 15.8\end{array}$

Combination therapy

$84.6 \quad 84.2$

\subsection{Complementary Medicine (CM) Use}

Of 58 participants, there were 57 (98\%) CM users, including dietary supplements, and only one non-user (female) who responded "I don't use or do anything outside of what my physician/health care provider prescribes." There were 51 participants $(87.9 \%)$ who used CM specifically as a cancer treatment. 


\subsubsection{Prevalence.}

Among all female participants, prayer was the most common CM modality used (94.9\%), followed by biologically-based therapies $(92.3 \%)$, specifically, dietary change $(87.2 \%)$ and dietary supplements $(79.5 \%)$. Among all male participants, biologically-based therapies were the most common CM modality used; specifically, dietary change $(79.0 \%)$ and dietary supplements $(79.0 \%)$, followed by prayer $(68.4 \%)$. Use of a CAM provider was the least common CM modality used among both females and males $(12.8 \% \& 10.5 \%$, respectively). Five percent (5.3\%) of females and $10.5 \%$ of males used prayer exclusively as their CM, and therefore used no other CM modality. Complementary medicine (CM) use is stratified by gender in Table 2 .

\subsubsection{Reasons to Use}

Eighty-nine percent $(89.7 \%$ ) of all females and $84.2 \%$ of all males reported using complementary medicine, of any modality, as a cancer therapy. Among females and males, the most common reason to use CM as a cancer therapy was "to help fight the cancer" ( $84.6 \%$ \& $79.0 \%$, respectively), followed by "to prevent recurrence" ( $76.3 \% \& 63.2 \%$, respectively). The least common reason to use $\mathrm{CM}$ as a cancer therapy, reported by females, was "to cure the cancer" $(69.2 \%)$, whereas men least reported that they used CM "to relieve their emotional symptoms" (47.2\%). Refer to Table 2.

Table 2. Prevalence (\%) of and reasons to use complementary medicine

\begin{tabular}{|c|c|c|}
\hline Complementary Medicine Use & $\begin{array}{l}\text { Females }(\%)^{*} \\
\mathbf{n}=39\end{array}$ & $\begin{array}{l}\text { Males }(\%)^{*} \\
n=19\end{array}$ \\
\hline Biologically-based therapies & 92.3 & 89.5 \\
\hline Dietary Change & 87.2 & 79.0 \\
\hline Dietary supplements $^{* *}$ & 79.5 & 79.0 \\
\hline Green Tea & 56.4 & 31.6 \\
\hline Herbal Tea & 46.2 & 21.1 \\
\hline Herbs or herbal supplements & 25.6 & 15.8 \\
\hline Mind-body therapies & 71.8 & 73.7 \\
\hline Movement-based relaxation & 18.0 & 15.8 \\
\hline Other relaxation & 43.6 & 52.6 \\
\hline Meditation & 38.5 & 26.3 \\
\hline Spirituality & 51.3 & 52.6 \\
\hline Prayer & 94.9 & 68.4 \\
\hline Prayer (exclusively) & 5.3 & 10.5 \\
\hline CAM provider & 10.3 & 10.5 \\
\hline CAM as a cancer therapy & 89.7 & 84.2 \\
\hline To relieve physical symptoms & 71.8 & 57.9 \\
\hline To relieve emotional symptoms & 74.4 & 47.4 \\
\hline To prevent recurrence & 76.3 & 63.2 \\
\hline To help fight the cancer & 84.6 & 79.0 \\
\hline To cure the cancer & 69.2 & 57.9 \\
\hline
\end{tabular}

* percentage of all female and male participants, respectively

${ }^{* *}$ vitamin, animal-origin, or micro-organism supplements

\# "yes" to any of the reasons below

\subsection{Demographic Predictors of CM Use}

\subsubsection{Gender}

Females were eight times more likely $(\mathrm{OR}=8.5)$ to use prayer as $\mathrm{CM}$ compared to males. Only two females reported they did not use prayer as CM. However, females were not more likely to use other CM modalities and were not more likely than men to use any type of $\mathrm{CM}$ as a cancer therapy. 


\subsubsection{Age}

Participants less than 60 years of age were 2.5 times more likely to report the use of prayer as CM compared to older participants $(\mathrm{OR}=2.556)$, yet were less likely to report the use of biologically-based $\mathrm{CM}(\mathrm{OR}=0.473)$ and mind-body therapies $(\mathrm{OR}=0.333)$. These point estimates indicate that participants 60 years of age or older were approximately twice as likely to report the use of biologically-based CM and three times as likely to report the use of mind-body therapies. Point estimates greater than or equal to two are noteworthy, though none were statistically significant.

\subsubsection{Ethnicity}

Hispanic participants were 3 times more likely to report use of mind-body therapies $(\mathrm{OR}=3.18)$. An odds ratio for use of any CM as a cancer therapy could not be computed, because all Hispanic participants reported to use $\mathrm{CM}$ as a cancer therapy.

\subsubsection{Race}

Caucasians were three times more likely to report the use of biologically-based CM $(\mathrm{OR}=3.00)$ compared to non-Caucasians. An odds ratio for use of prayer and use of any CM as a cancer therapy could not be computed because all non-Caucasians used prayer and any CM as a cancer therapy. An odds ratio for use of a CAM provider could not be computed because zero non-Caucasians reported to use a CAM provider (Table 3). Each predictor in the univariate model had greater than $90 \%$ power.

Table 3. Odds ratios to determine predictors of CM use - univariate analysis

\begin{tabular}{llllll}
\hline Predictor & Biologically-based & $\begin{array}{l}\text { Mind-Body } \\
\text { Therapies }\end{array}$ & Prayer & CAM Provider & $\begin{array}{l}\text { Use of CM as a } \\
\text { cancer therapy }\end{array}$ \\
\hline Female & 1.41 & 0.91 & $8.54^{*}$ & 0.97 & 1.64 \\
Male & 1.00 & 1.00 & 1.00 & 1.00 & 1.00 \\
18 - 60 years & 0.47 & 0.33 & 2.56 & 0.63 & 1.01 \\
$\geq 60$ years & 1.00 & 1.00 & 1.00 & 1.00 & 1.00 \\
Hispanic & 0.64 & 3.18 & 1.00 & $1.14 *$ & 1.00 \\
non-Hispanic & 1.00 & 1.00 & 1.00 & 1.00 & $\#$ \\
Caucasian** & 3.00 & 0.76 & $\#$ & 1.00 & $*$ \\
Non-Caucasian & 1.00 & 1.00 & 1.00 & & $*$ \\
* Statistically significant value (p-value $<0.05)$ & ${ }^{\#}$ Cell contains zero, thus cannot compute OR &
\end{tabular}

\subsection{Disclosure of CM Use}

\subsubsection{Prevalence}

Forty participants were asked questions regarding disclosure of $\mathrm{CM}$ use. The majority of participants reported to have disclosed their $\mathrm{CM}$ use to a health care provider, and proportionally more women than men had disclosed ( $72.0 \% \& 53.3 \%$, respectively). Of those who reported to have disclosed their CM use, disclosure to an oncologist was the most common (66.7\% among females \& $50.0 \%$ among males), followed by disclosure to a primary care physician (38.9\% among females \& $37.5 \%$ among males) and disclosure to a nurse $(22.2 \%$ among females \& $37.5 \%$ among males). Over one third of females (38.9\%) and $12.5 \%$ of males reported to have disclosed their $\mathrm{CM}$ use to more than one health care provider.

Those who reported to not have disclosed their CM use to a health care provider were asked who they were most likely to tell. Most responded they would disclose to family and/or friends $(28.6 \%$ among females \& $42.9 \%$ among males), a primary care physician (28.6\% among females \& $28.6 \%$ among males), or an oncologist (28.6\% among females \& $14.3 \%$ among males). Less men than women reported they would disclose to a physician (Table 4). 
Table 4. Disclosure of complementary medicine use to a health care provider

\begin{tabular}{|c|c|c|}
\hline $\begin{array}{l}\text { Did you disclose your complementary } \\
\text { medicine use to a health care provider? }\end{array}$ & $\begin{array}{l}\text { Females }(\%) \\
n=25^{*}\end{array}$ & $\begin{array}{l}\text { Males (\%) } \\
\mathrm{n}=15^{*}\end{array}$ \\
\hline Yes & 72.0 & 53.3 \\
\hline No & 28.0 & 46.7 \\
\hline If yes, to whom? ${ }^{\#}$ & $\mathrm{n}=18$ & $\mathrm{n}=8$ \\
\hline Oncologist & 66.7 & 50.0 \\
\hline Nurses & 22.2 & 37.5 \\
\hline Primary care physician $^{* *}$ & 38.9 & 37.5 \\
\hline Dietician/Nutritionist & 16.7 & 25.0 \\
\hline Radiologist & 5.6 & 37.5 \\
\hline PA & 0.0 & 6.7 \\
\hline More than 1 & 38.9 & 12.5 \\
\hline If no, who are you most likely to tell? ${ }^{\#}$ & $\mathrm{n}=7$ & $\mathrm{n}=7$ \\
\hline Family and/or friends & 28.6 & 42.9 \\
\hline Primary care physician ${ }^{* *}$ & 28.6 & 28.6 \\
\hline Oncologist & 28.6 & 14.3 \\
\hline Insurance provider & 14.3 & 14.3 \\
\hline No one & 14.3 & 0 \\
\hline I don't know & 0 & 14.3 \\
\hline More than 1 & 0 & 14.3 \\
\hline
\end{tabular}

*This question was not on the first 18 surveys administered. Female who did not currently use any CAM excluded. Open-ended question. $\quad$ ** Other terms used were "general practitioner," "family physician," or "physician."

\subsubsection{Reasons to Disclose}

Participants $(n=40)$ were asked to pick the statement that best completed this sentence: "Sometimes I do not ask or tell my oncologist about my CAM use because...." Out of seven formatted responses and "other," which allowed for an open-ended response, the most common response was because "he/she is most concerned about my cancer and cancer treatment" $(27.5 \%)$ and "other" $(27.5 \%)$, followed by "I just did not think to tell $\mathrm{him} /$ her" $(22.5 \%)$. The most common reason participants $(\mathrm{n}=11)$ reported to have selected "other" was because they tell their providers $(72.7 \%)$. Other open-ended responses were "I'm comfortable speaking with my physician(s)" (18.2\%) and "he told me to take these things [CAM]" (9.1\%). Refer to Table 5.

Table 5. Reasons to disclose or not to disclose use of complementary medicine to a health care provider

\begin{tabular}{|c|c|}
\hline $\begin{array}{l}\text { Pick the statement that best completes this sentence: Sometimes I do not ask or } \\
\text { tell my oncologist about my CAM use because, }\end{array}$ & $\begin{array}{r}(\%) \\
n=40\end{array}$ \\
\hline $\mathrm{He} /$ she is most concerned about my physical well-being & 10.0 \\
\hline $\mathrm{He} /$ she is most concerned about my cancer and cancer treatment & 27.5 \\
\hline I just did not think to tell him/her & 22.5 \\
\hline I feel more comfortable talking to another health care provider. & 2.5 \\
\hline I feel that I will be judged. & 2.5 \\
\hline I feel that my oncologist will view me negatively. & 2.5 \\
\hline "I don’t know" & 5.0 \\
\hline Other ${ }^{* *}$ & 27.5 \\
\hline "I tell my providers" & 72.7 \\
\hline "I'm comfortable speaking with physician" & 18.2 \\
\hline "He told me to take these things [CAM]" & 9.1 \\
\hline
\end{tabular}




\section{Discussion}

Our findings indicate a very high prevalence of complementary medicine (CM) use among cancer patients receiving conventional treatment at Loma Linda University Medical Center (LLUMC). Although the prevalences found for use of different CM modalities were wide-ranging (10\% to $95 \%$ ), an $88 \%$ prevalence for any type of CM use as a cancer therapy was higher than other estimates, which typically range from $40 \%$ to $83 \%$ (Boon et al., 2000; Buettner et al., 2006; Cassileth et al., 1984; DiGianni et al., 2002; Ernst \& Cassileth, 1998; Ganz et al., 2002; Greenlee et al., 2009; Habermann et al., 2009; Henderson \& Donatelle, 2004; Lawsin et al., 2007; Lee et al., 2000; Lo et al., 2009; Mao et al., 2007; Mao, 2011; Morris et al., 2000; Richardson et al., 2000; Saxe et al., 2008; Yap, 2004). The reported disclosure proportions in this study (72\% among women and $53 \%$ among men) were higher than the general population's estimate for CM disclosure, but comparable to other reported disclosure proportions among patients with a serious illness (47\% to 85\%) (Chao et al., 2008; Saxe et al., 2008). Our main findings are (1) differentiating CM modalities shows that different prevalences exist for each modality, (2) differentiating CM modalities shows that different predictors of CM use exist for each modality, (3) reasons to use $\mathrm{CM}$ vary by gender, and (4) disclosure proportions also vary by gender.

\subsection{Use}

While overall CM use was more prevalent among women as found in other studies (Barraco et al., 2005; F. L. Bishop \& Lewith, 2010; Lawsin et al., 2007), trends of most prevalent CM modalities found in this study were similar among women and men. For instance, biologically-based CM therapies were most popular among both women $(92.3 \%)$ and men $(89.5 \%)$ and use of a CAM provider was least popular (10\%) (Gansler et al., 2008; J. Mao et al., 2008; Richardson et al., 2004; Upchurch, 2007; Wade, Chao, Kronenberg, Cushman, \& Kalmuss, 2008). Within types of biologically-based therapies, dietary change and dietary supplements were most prevalent, followed by green tea, herbal tea, and herbs or herbal supplements for both genders. Similarly, trends for the different types of mind-body therapies were comparable among both genders; prayer and spirituality were most popular and movement-based relaxation was least utilized as $\mathrm{CM}$. These results are in line with other studies that find a high use of prayer as CM (Bishop \& Lewith, 2010; Gansler et al., 2008; Lawsin et al., 2007; J. J. Mao et al., 2007; Richardson et al., 2004; Richardson et al., 2000) and a lower utilization of a CAM provider (Gansler et al., 2008; J. Mao et al., 2008; Richardson et al., 2004). In addition, women were eight times more likely to use prayer as CM for general health compared to men, as supported by other studies (Gansler et al., 2008; Sleath et al., 2005).

Our unadjusted univariate analyses differed from other demographic studies that found that Caucasian, younger female cancer patients of higher education were more likely to utilize CM (Bishop \& Lewith, 2008; Bishop \& Lewith, 2010; Lawsin et al., 2007). Our study demonstrated that CM use, specifically as a cancer therapy, did not significantly vary by gender, age, or education. Other studies that reported CM usage from under-represented populations have found that $\mathrm{CM}$ use was high among poor, older, and ethnic minority adults (Goldstein et al., 2005). This inclusivity of results may contribute to our null findings when analyzing the overall use of CM among a heterogeneous group of patients. Furthermore, it indicates the importance of differentiating CM modalities when assessing $\mathrm{CM}$ use among cancer patients.

Associations between race, ethnicity and CM use remain uncertain. Approximately 38 studies have shown that minority groups use $\mathrm{CM}$ less than Caucasians, whereas at least 15 studies have found that minority groups use CM more (Bishop \& Lewith, 2008; Goldstein et al., 2005). Divergent findings may in part be due to underrepresented populations, for example, minority groups accounting for only approximately $10 \%$ of a sample population (Gansler et al., 2008; Goldstein et al., 2005), and types of CM included in a study (Hsiao et al., 2006). Our findings do not resolve this uncertainty. All Hispanic and non-Caucasian participants used at least one CM modality as a cancer therapy, but none of them used a CAM provider.

The reasons to use CM varied by gender. More than two-thirds of the women responded 'yes' to each of the reasons listed on the survey, suggesting women sought and used $\mathrm{CM}$ as a medical pluralistic approach to help them better achieve holistic well-being (Belliard, 2005; NCCAM, 2010; Richardson et al., 2004). Other reasons for increased use among women, reported by past studies, include a greater sense of control of self, a more personal focus on health, and an overall increased use of health/medical services (Brett, 2001; Gansler et al., 2008).

\subsection{Disclosure of CM Use}

Our findings are consistent with prior studies that too have reported a higher disclosure rate among patients with a life-threatening illness compared to the general adult population (Goldstein et al., 2005; Richardson et al., 2004; Saxe et al., 2008; Sleath et al., 2005). Our findings are also consistent with prior data that women are more likely 
to disclose their CM use to a health care provider than men (Harrigan, 2011; NCCAM, 2010; Richardson et al., 2004). Women were also more likely to tell more than one health care provider. Reasons for this higher disclosure rate among women may be because women tend to see doctors more often (Brett, 2001), ask more questions, and have longer encounters with physicians compared to men (Falik, 1996; Richardson et al., 2004). All respondents were more likely to disclose CM use to a physician (NCCAM, 2010) rather than another healthcare provider.

The most common reason cited for a patient's non-disclosure of his/her CM use to the oncologist was because the patient perceived the role of the oncologist to be most concerned with cancer and cancer treatment. While there is no perfectly comparable research, findings reported by NCCAM $(2010 \& 2006)$ stated that the number one reported reason for a patient's non-disclosure was that the health care provider never asked the patient, followed by the response that the patient didn't know he/she should disclose (NCCAM, 2010). In addition, a higher proportion of men reported to disclose their CAM use to a friend or relative as opposed to a health care provider. Among the general population, non-disclosure to a health care provider among men may be related to the lower utilization of health care compared to women (Bonhomme, 2007; Brett, 2001; Brott et al., 2011), however, male cancer patients would see their physicians as much as women. It may simply be because women more often take an active role in their health care compared to men (Bonhomme, 2007; Brett, 2001). Nevertheless, there is a lack of literature on reasons for or against disclosure of CAM use.

\subsection{Strengths \& Limitations}

This study has a number of limitations. As this was a non-randomized, small, convenience sample, there is potential for systematic bias. However, selection methods were designed to reduce selection bias by sampling over a period of time, on every day of the week, and at various times during the day, and were inclusive of all patient types. While investigator/interviewer biases are possible, interviewers were trained to follow protocol to recruit participants and a standardized method to survey administration was used. The small sample sizes after stratification made it difficult to compute an accurate and fully-adjusted model of demographic predictors of CM use. However, in a univariate model, statistical power exceeded $90 \%$ for each predictor.

Despite these limitations, our study provides a variety of insights on CM use among cancer patients. The inclusion of minorities and their high prevalence of $\mathrm{CM}$ use sheds light on the practice of medical pluralism (Belliard, 2005). Differentiating CM modalities as separate outcome variables not only adjusts for confounding by $\mathrm{CM}$ modality, but illustrates that predictor variables among the $\mathrm{CM}$ modalities are different. Because this is a cancer population, making a distinction between CM modalities that can interact with conventional treatment, such as herbs or antioxidants interacting with chemotherapy, is vital (Hietala et al., 2011; Thomas-Schoemann et al., 2011). Selection bias was reduced do to recruiting face-to-face which gave us a very high response rate. Lastly, the survey tool used and survey administration were a part of a mix-methods study design to limit information bias and improve validity of the data.

\subsection{Conclusion}

Future research should repeat this present study in a community hospital setting to increase sample size, increase the range of patient characteristics, and to be more inclusive of minorities and low SES patients. Further investigation is required to better determine an association between race, ethnicity, age, sex, SES and CAM use among cancer patients. CAM use should be differentiated by CAM modalities, as it is likely that lower SES cancer patients will not be financially able to seek expensive CAM modalities, such as a CAM provider (Richardson et al., 2004). Because possible interactions exist with certain cancer treatments, these findings of high CM use among patients undergoing such treatments iterates the importance of CAM efficacy studies.

The high utilization of CAM among cancer patients and non-disclosure proportions suggests the implementation of integrative medicine may improve physician-patient relationships, influence health care providers to provide patients with the risks and benefits of CAM use, which may improve survivor quality of life, and may help prioritize research investigating reasons to use CAM and efficacy and safety of CAM use.

\section{Acknowledgments}

We want to thank and acknowledge the support and cooperation from Dr. CS Chen, MD, PhD and the LLUMC Cancer Center and its infusion nurses. We want to thank all participants for their time and willingness to participate in the surveys. We'd also like to recognize the LLU School of Public Health graduate research assistants for their contributions. 


\section{References}

Barnes, P. M., Bloom, B., \& Nahin, R. L. (2008). Complementary and Alternative Medicine Use Among Adults and Children: United States, 2007. In N. C. f. H. S. Reports (Ed.), (Vol. 12). Hyattsville, MD.

Barraco, D., Valencia, G., Riba, A. L., Nareddy, S., Draus, C., \& Schwartz, S. M. (2005). Complementary and alternative medicine (CAM) use patterns and disclosure to physicians in acute coronary syndromes patients. Complementary Therapies in Medicine, 13(1), 34-40. http://dx.doi.org/10.1016/j.ctim.2005.02.003

Bell, R. M. (2010). A Review of Complementary and Alternative Medicine Practices Among Cancer Survivors. Clinical Journal of Oncology Nursing, 14(3), 365-370. http://dx.doi.org/10.1188/10.cjon.365-370

Belliard, J. C., \& Ramírez-Johnson, J. (2005). Medical Pluralism in the Life of a Mexican Immigrant Woman. Hispanic Journal of Behavioral Sciences, 27(3), 267-285.

Ben-Arye, E., \& Frenkel, M. (2008). Referring to complementary and alternative medicine-A possible tool for implementation. Complementary Therapies in Medicine, 16(6), 325-330. http://dx.doi.org/10.1016/j.ctim.2008.02.008

Bishop, F., \& Lewith, G. (2008). Who Uses CAM? A Narrative Review of Demographic Characteristics and Health Factors Associated with CAM Use. Evidence Based Complementary Alternative Medicine, 7(1), 11-28.

Bishop, F. L., \& Lewith, G. T. (2010). Who Uses CAM A Narrative Review of Demographic Characteristics and Health Factors Associated with CAM Use. Evidence-Based Complementary and Alternative Medicine, 7(1), 11-28. http://dx.doi.org/10.1093/ecam/nen023

Bonhomme, J. J. (2007). Men's Health: Key to Healthier Women, Children, and Communities. American Journal of Mens Health, 1(4), 335-338. http://dx.doi.org/10.1177/1557988306297261

Boon, H., Stewart, M., Kennard, M. A., Gray, P., Sawka, C., Brown, J. B., ... Haines-Kamka, T. (2000). Use of complementary/alternative medicine by breast cancer survivors in Ontario: Prevalence and perceptions. Journal of Clinical Oncology, 18(13), 2515-2521.

Brett, K. M., \& Burt, C. W. (2001). Utilization of ambulatory medical care by women: United States, 1997-98. Vital \& Health Statistics-Series: National Health Survey.

Brott, A., Dougherty, A., Williams, S. T., Matope, J. H., Fadich, A., \& Taddelle, M. (2011). The Economic Burden Shouldered by Public and Private Entities as a Consequence of Health Disparities Between Men and Women. American Journal of Mens Health, 5(6), 528-539. http://dx.doi.org/10.1177/1557988311421214

Buettner, C., Kroenke, C. H., Phillips, R. S., Davis, R. B., Eisenberg, D. M., \& Holmes, M. D. (2006). Correlates of use of different types of complementary and alternative medicine by breast cancer survivors in the nurses' health study. Breast Cancer Research and Treatment, 100(2), 219-227. http://dx.doi.org/10.1007/s10549-006-9239-3

Cassileth, B. R., Lusk, E. J., Strouse, T. B., \& Bodenheimer, B. J. (1984). Contemporary unorthodox treatments in cancer medicine - a stdy of patients, treatments, and practitioners. Annals of Internal Medicine, 101(1), 105-112.

Chao, M. T., Wade, C., \& Kronenberg, F. (2008). Disclosure of Complementary and Alternative Medicine to Conventional Medical Providers: Variation by Race/Ethnicity and Type of CAM. Journal of the National Medical Association, 100(11), 1341-1349.

Denzin, N. K. (1970). The research act in sociology. Chicago: Aldine.

DiGianni, L. M., Garber, J. E., \& Winer, E. P. (2002). Complementary and alternative medicine use among women with breast cancer. Journal of Clinical Oncology, 20(18), 34S-38S. http://dx.doi.org/10.1200/jco.2002.07.176

Ernst, E., \& Cassileth, B. R. (1998). The prevalence of complementary/alternative medicine in cancer - A systematic review. Cancer, 83(4), 777-782.

Falik, M., \& Collins, K. (eds.) (1996). The Commonwealth Fund Survey of Women's Health: Selected facts on U.S. women's health The Commonwealth Fund. Baltimore, MD: Johns Hopkins University Press.

Gansler, T., Kaw, C., Crammer, C., \& Smith, T. (2008). A population-based study of prevalence of complementary methods use by cancer survivors - A report from the American cancer society's studies of cancer survivors. Cancer, 113(5), 1048-1057. http://dx.doi.org/10.1002/cncr.23659 
Ganz, P. A., Desmond, K. A., Leedham, B., Rowland, J. H., Meyerowitz, B. E., \& Belin, T. R. (2002). Quality of life in long-term, disease-free survivors of breast cancer: a follow-up study. Journal of the National Cancer Institute, 94(1), 39-49.

Goldstein, M. S., Brown, E. R., Ballard-Barbash, R., Morgenstern, H., Bastani, R., Lee, J., ... Ambs, A. (2005). The use of complementary and alternative medicine among California adults with and without cancer. Evidence-Based Complementary and Alternative Medicine, 2(4), 557-565. http://dx.doi.org/10.1093/ecam/neh138

Greenlee, H., Kwan, M. L., Ergas, I. J., Sherman, K. J., Krathwohl, S. E., Bonnell, C., ... Kushi, L. H. (2009). Complementary and alternative therapy use before and after breast cancer diagnosis: the Pathways Study. Breast Cancer Research and Treatment, 117(3), 653-665. http://dx.doi.org/10.1007/s10549-009-0315-3

Habermann, T. M., Thompson, C. A., LaPlant, B. R., Bauer, B. A., Janney, C. A., Clark, M. M., ... Cerhan, J. R. (2009). Complementary and alternative medicine use among long-term lymphoma survivors: A pilot study. American Journal of Hematology, 84(12), 795-798. http://dx.doi.org/10.1002/ajh.21554

Harrigan, J. T. (2011). Patient disclosure of the use of complementary and alternative medicine to their obstetrician/gynaecologist. Journal of Obstetrics and Gynaecology, 31(1), 59-61. http://dx.doi.org/10.3109/01443615.2010.531303

Harris, P., \& Rees, R. (2000). The prevalence of complementary and alternative medicine use among the general population: a systematic review of the literature. Complementary Therapies in Medicine, 8(2), 88-96.

Henderson, J. W., \& Donatelle, R. J. (2004). Complementary and alternative medicine use by women after completion of allopathic treatment for breast cancer. Alternative Therapies in Health and Medicine, 10(1), $52-57$.

Hietala, M., Henningson, M., Ingvar, C., Jonsson, P. E., Rose, C., \& Jernstrom, H. (2011). Natural remedy use in a prospective cohort of breast cancer patients in southern Sweden. Acta Oncologica, 50(1), 134-143. http://dx.doi.org/10.3109/0284186x.2010.484812

Hsiao, A. F., Wong, M. D., Goldstein, M. S., Yu, H. J., Andersen, R. M., Brown, E. R., ... Wenger, N. S. (2006). Variation in complementary and alternative medicine (CAM) use across racial/ethnic groups and the development of ethnic-specific measures of CAM use. Journal of Alternative and Complementary Medicine, 12(3), 281-290.

Kennedy, J. (2005). Herb and supplement use in the US adult population. Clinical Therapeutics, 27(11), 1847-1858. http://dx.doi.org/10.1016/j.clinthera.2005.11.004

Lawsin, C., DuHamel, K., Itzkowitz, S. H., Brown, K., Lim, H., Thelemaque, L., \& Jandorf, L. (2007). Demographic, medical, and psychosocial correlates to CAM use among survivors of colorectal cancer. Supportive Care in Cancer, 15(5), 557-564. http://dx.doi.org/10.1007/s00520-006-0198-3

Lee, M. M., Lin, S. S., Wrensch, M. R., Adler, S. R., \& Eisenberg, D. (2000). Alternative therapies used by women with breast cancer in four ethnic populations. Journal of the National Cancer Institute, 92(1), 42-47.

Lo, C. B., Desmond, R. A., \& Meleth, S. (2009). Inclusion of Complementary and Alternative Medicine in US State Comprehensive Cancer Control Plans: Baseline Data. Journal of Cancer Education, 24(4), 249-253. http://dx.doi.org/10.1080/08858190902972897

Mao, J. J., Farrar, J. T., Xie, S. X., Bowman, M. A., \& Armstrong, K. (2007). Use of complementary and alternative medicine and prayer among a national sample of cancer survivors compared to other populations without cancer. Complementary Therapies in Medicine, 15(1), 21-29. http://dx.doi.org/10.1016/j.ctim.2006.07.006

Mao, J., Palmer, S., Straton, J., Cronholm, P., Keddem, S., Knott, K., \& Barg, F. (2008). Cancer survivors with unmet needs were more likely to use complementary and alternative medicine. Journal of Cancer Survivorship, 2, 116-124.

Mao, J. J., Palmer, C. S., Healy, K. E., Desai, K., \& Amsterdam, J. (2011). Complementary and alternative medicine use among cancer survivors: a population-based study. Journal cancer survivorship, 5(1), 8-17.

Morgan, J. W., Koch, S. M., Imai, C., \& Cassady, R. E. (2009). Cancer incidence and mortality in Inyo, Mono, Riverside, and San Bernardino counties, 1988 - 2007 Region 5 of the California Cancer Registry. Loma Linda University Medical Center.

Morris, K. T., Johnson, N., Homer, L., \& Walts, D. (2000). A comparison of complementary therapy use 
between breast cancer patients and patients with other primary tumor sites. American Journal of Surgery, 179(5), 407-411.

National Center for Complementary and Alternative Medicine (NCCAM). (2010). What Is Complementary and Alternative Medicine? Retrieved April 19, 2013, from http://nccam.nih.gov/health/whatiscam/

NCCAM, \& AARP. (2010). Complementary and Alternative Medicine: What People Aged 50 and Older Discuss With Their Health Care Providers. Consumer Survey Report (Vol. 2011).

NCI. Definition of spirituality. Retrieved April 19, 2013, from http:/www.cancer.gov/dictionary?cdrid=441265

Pappas, S., \& Perlman, A. (2002). Complementary and alternative medicine - The importance of doctor-patient communication. Medical Clinics of North America, 86(1), 1.

Reeves, M. (2010). Cancer program annual report. Loma Linda, CA: Loma Linda University Cancer Center

Richardson, M. A., Masse, L. C., Nanny, K., \& Sanders, C. (2004). Discrepant views of oncologists and cancer patients on complementary/alternative medicine. Supportive Care in Cancer, 12(11), $797-804$. http://dx.doi.org/10.1007/s00520-004-0677-3

Richardson, M. A., Sanders, T., Palmer, J. L., Greisinger, A., \& Singletary, S. E. (2000). Complementary/alternative medicine use in a comprehensive cancer center and the implications for oncology. Journal of Clinical Oncology, 18(13), 2505-2514.

Robinson, A., \& McGrail, M. R. (2004). Disclosure of CAM use to medical practitioners: a review of qualitative and quantitative studies. Complementary Therapies in Medicine, 12(2-3), 90-98. http://dx.doi.org/10.1016/j.ctim.2004.09.006

Saxe, G. A., Madlensky, L., Kealey, S., Wu, D. P. H., Freeman, K. L., \& Pierce, J. P. (2008). Disclosure to physicians of CAM use by breast cancer patients: Findings from the Women's Healthy Eating and Living Study. Integrative Cancer Therapies, 7(3), 122-129. http://dx.doi.org/10.1177/1534735408323081

Singh, H., Maskarinec, G., \& Shumay, D. M. (2005). Understanding the Motivation for Conventional and Complementary/Alternative Medicine Use Among Men With Prostate Cancer. Integrative Cancer Therapies, 4(2), 187-194.

Sleath, B., Callahan, L., DeVellis, R. F., \& Sloane, P. D. (2005). Patients' perceptions of primary care physicians' participatory decision-making style and communication about complementary and alternative medicine for arthritis. Journal of Alternative and Complementary Medicine, 11(3), 449-453.

Thomas-Schoemann, A., Alexandre, J., Mongaret, C., Azibi, S., Dauphin, A., Goldwasser, F., \& Lemare, F. (2011). Use of antioxidant and other complementary medicine by patients treated by antitumor chemotherapy: a prospective study. Bulletin Du Cancer, 98(6), 645-653. http://dx.doi.org/10.1684/bdc.2011.1375

Upchurch, D. M., Chyu, L., Greendale, G. A., Utts, J., Bair, Y. A., Zhang, G., \& Gold, E. B. (2007). Use of complementary and alternative medicine among American women: Findings from the National Health Inverview Survey, 2002. Journal of Womens Health, 16(1), 102-113.

Velicer, C. M., \& Ulrich, C. M. (2008). Vitamin and mineral supplement use among US adults after cancer diagnosis: A systematic review. Journal of Clinical Oncology, 26(4), 665-673. http://dx.doi.org/10.1200/jco.2007.13.5905

Wade, C., Chao, M., Kronenberg, F., Cushman, L., \& Kalmuss, D. (2008). Medical pluralism among American women: Results of a national survey. Journal of Womens Health, 17(5), 829-840. http://dx.doi.org/10.1089/jwh.2007.0579

Yap, K. P., McCready, D. R., Fyles, A., Manchul, L., Trudeau, M., \& Narod, S. (2004). Use of alternative therapy in postmenopausal breast cancer patients treated with tamoxifen after surgery. Breast J, 10, 481-486.

\section{Copyrights}

Copyright for this article is retained by the author(s), with first publication rights granted to the journal.

This is an open-access article distributed under the terms and conditions of the Creative Commons Attribution license (http://creativecommons.org/licenses/by/3.0/). 